\title{
El Crédito en el Perú entre los más caros del Mundo
}

\author{
Credit in Peru Among
}

World's Most Expensive

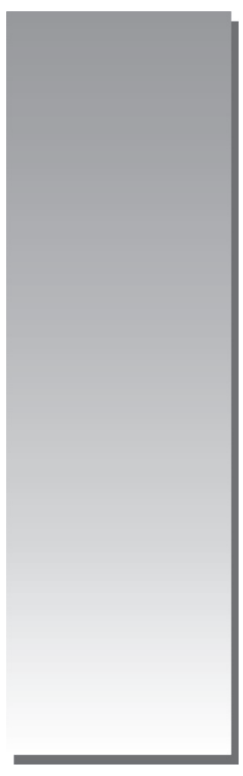

Pablo Mauricio Pachas

pmauriciop@unmsm.edu.pe

[RECEPCIÓN: AGOSTO 2016 / CONFORMIDAD: OCTUBRE 2016]

\section{RESUMEN}

El objetivo de la investigación es identificar los efectos del costo del dinero en el sistema financiero peruano sobre el desarrollo de las empresas y su tasa de informalidad. Mediante el método del estudio cualitativo, de diseño descriptivo correlacional, se realizó un estudio comparativo con la información histórica del sistema financiero peruano en relación con la de países modelo. Además de usar indicadores financieros de aceptación internacional.

Se evidenció que el alto costo del dinero en el sistema financiero peruano impacta negativamente en el desarrollo de la microempresa; a su vez, estas recurren a la informalidad como solución a su demanda de capital. La situación de las microempresas frente a la demanda de dinero puede ser solucionada a través de estrategias de apoyo y promoción efectiva; de esta manera, se reduciría el actual nivel de informalidad. Asimismo, el impacto positivo de estas estrategias mejoraría el nivel patrimonial de las microempresas.

Palabras clave: Dinero, préstamos, spread

\section{ABSTRACT}

The objective of the research is to identify the effects of the cost of money in the Peruvian financial system on the development of companies and the rate of informality in them. Methods of qualitative study, descriptive correlational design; A comparative study was analyzed with the historical information of the Peruvian financial system in relation to that of model countries. In addition to using financial indicators of international acceptance.

It was evidenced that high cost of money in the Peruvian financial system, has a negative impact on the development of microenterprise, in turn, they resort to informality as a solution to their demand for capital. The situation of microenterprises facing the demand for money can be solved through strategies of effective support and promotion, thus reducing the current level of informality. Likewise, the positive impact of these strategies would improve the equity level of microenterprises.

Keywords: money, loans, spread 


\section{INTRODUCCIÓN}

A partir de la última crisis financiera internacional, que impactó a todas las economías del mundo en diciembre del 2008, se baja la tasa de interés de referencia FED de EE.UU., de 5.25\% a nivel cercano a cero, para afrontar la gran recesión, que, como referente en los mercados financieros internacionales, abarata el costo del crédito a nivel mundial, por lo que resulta importante tratar esta baja del costo del dinero y compararlas con el costo del crédito o préstamos en nuestro país.

Se destaca la tasa de interés de los préstamos en el mercado internacional a través de la tasa Libor, que se mantiene baja desde el 2009 y que registra $1.16 \%$, actualmente (2015) muy por debajo del 5.34\%, que registró en el 2007. Sin embargo, en el sistema financiero peruano se mantiene alta la tasa de interés para créditos o préstamos, y para los ahorros se les aplican bajas tasas de interés, generando pérdida o tasa real negativa, como se puede observar desde el año 2007 a la fecha, en que la inflación supera a la tasa de interés que se paga por ahorros.

El objetivo es exponer que los créditos ofertados por entidades del sistema financiero peruano (SFP) se encuentran entre los más caros del mundo, al describir elevados márgenes o spread. Tal spread es determinado por la diferencia entre las tasas de interés que cobran por los créditos, TAMN y las tasas de interés que pagan por los ahorros, TIPMN, aún elevados. Esta característica se puede apreciar entre 1992-2015, que si bien comenzó a descender a inicio de los 90, se mantienen altos, como ocurre actualmente (2015). El spread", en términos promedio, es del $13.84 \%$, alrededor de seis veces lo que se paga por los ahorros, comportamiento que explica la elevada rentabilidad que obtienen los bancos y financieras en el Perú.

El SFP, al registrar uno de los más altos márgenes o spread del mundo, es calificado como uno de los países con los peores spread del mundo, característica que se destaca en los spread de los años 2010 y 2014. En el 2010, nuestro país registró $17.5 \%$ de spread, seguidos por otros de Latinoamérica, como Brasil con $31.1 \%$, Paraguay con 24.8\%; luego en el año 2014 nuestro país registra $14 \%$, Brasil $21.98 \%$ y Paraguay $16.88 \%$, comportamiento que aún mantienen más spread

\footnotetext{
Superintendencia de Banca y Seguros del Perú. (2016). Tasas de Interes. 08 maarzo, 2016, de SBS GOB Sitio web: http://www.sbs.gob.pe/app/pp/seriesHistoricas/paso5_ Descargar.aspx ?cod $=4 \&$ per $=6 \&$ paso $=3 \&$ secu $=02$
}

del mundo.

\section{MÉTODOS}

Estudio cualitativo de diseño descriptivo correlacional. Se comparó un estudio comparativo con la información histórica del sistema financiero peruano en relación con la de países modelo. Además de usar indicadores financieros de aceptación internacional.

\section{RESULTADOS \\ EL CRÉDITO EN EL SISTEMA FINANCIERO PERUANO (SFP) ES CARO \\ Fuente: 585}

\section{Cuadro $\mathrm{N}^{0} 1$. Préstamos y ahorros en} moneda nacional: 1992-2015

\begin{tabular}{l|c|c|c}
\hline AÑ & TAMN & TIPMN & $\begin{array}{c}\text { MARGEN } \\
\text { (SPREAD) }\end{array}$ \\
1992 & $135.50 \%$ & $18.15 \%$ & $117.35 \%$ \\
1993 & $71.50 \%$ & $18.20 \%$ & $53.30 \%$ \\
1994 & $39.00 \%$ & $7.30 \%$ & $31.70 \%$ \\
1995 & $35.10 \%$ & $9.90 \%$ & $25.20 \%$ \\
1996 & $30.06 \%$ & $10.50 \%$ & $19.56 \%$ \\
1997 & $30.04 \%$ & $9.90 \%$ & $20.14 \%$ \\
1998 & $32.06 \%$ & $12.50 \%$ & $19.46 \%$ \\
1999 & $32.33 \%$ & $10.49 \%$ & $21.84 \%$ \\
2000 & $32.33 \%$ & $9.70 \%$ & $22.63 \%$ \\
2001 & $24.98 \%$ & $7.57 \%$ & $17.41 \%$ \\
2002 & $20.97 \%$ & $3.54 \%$ & $17.43 \%$ \\
2003 & $21.02 \%$ & $3.11 \%$ & $17.91 \%$ \\
2004 & $24.79 \%$ & $2.42 \%$ & $22.37 \%$ \\
2005 & $25.42 \%$ & $2.59 \%$ & $22.83 \%$ \\
2006 & $23.39 \%$ & $3.21 \%$ & $20.18 \%$ \\
2007 & $22.87 \%$ & $3.23 \%$ & $19.64 \%$ \\
2008 & $23.68 \%$ & $3.50 \%$ & $20.18 \%$ \\
2009 & $22.95 \%$ & $2.84 \%$ & $20.11 \%$ \\
2010 & $18.98 \%$ & $1.53 \%$ & $17.45 \%$ \\
2011 & $18.68 \%$ & $2.34 \%$ & $16.34 \%$ \\
2012 & $19.25 \%$ & $2.06 \%$ & $17.19 \%$ \\
2013 & $21.06 \%$ & $2.35 \%$ & $18.71 \%$ \\
2014 & $16.26 \%$ & $2.26 \%$ & $14.00 \%$ \\
2015 & $16.26 \%$ & $2.42 \%$ & $13.84 \%$ \\
\hline
\end{tabular}

Elaboración: Propia del autor.

Los créditos ofertados por entidades del SFP se encuentran entre los más caros del mundo, al describir elevados márgenes o spread. Tal spread es determinado por la diferencia entre las tasas de interés que cobran por los créditos, TAMN y las tasas de interés que pagan por los ahorros, TIPMN, aún elevados. Esta característica se puede apreciar entre 1992-2015, que si bien comenzó a descender a inicio de los 90, aún se mantienen 
altos, como ocurre actualmente (2015). El spread" ,en términos promedio, es del $13.84 \%$, alrededor de seis veces lo que se paga por los ahorros, comportamiento que explica la elevada rentabilidad que obtienen los bancos y financieras en el Perú. El elevado spread en soles, en términos promedio, se puede observar en el siguiente cuadro 01 y gráfico 01:

Gráfico $N^{0} 1$. Préstamos y ahorros en moneda nacional: 1992-2015

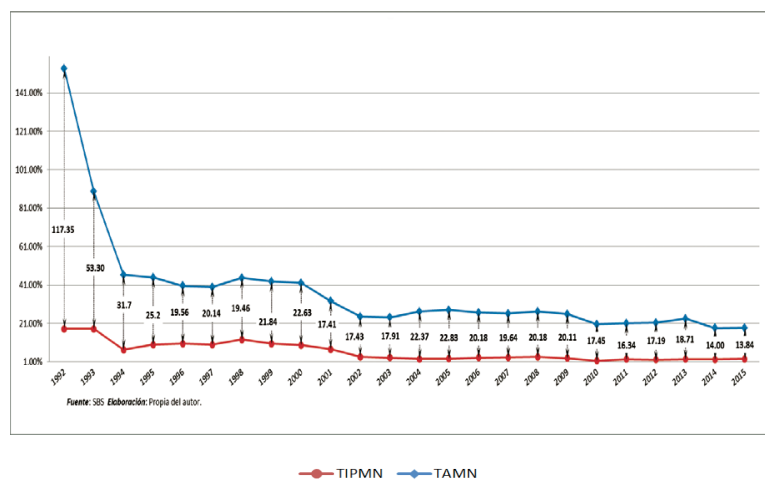

Tal como se observa en el gráfico $\mathrm{N}^{\circ} 01$, desde 1992 al 2015, la diferencia entre la tasa que se cobra por préstamos y las que se pagan por los ahorros, considerada como márgenes o spread, se mantiene elevada de manera sostenida desde 1996 al registrar este año $19.56 \%$, posteriormente $20.11 \%$ en el 2009 y $18.71 \%$ registrado en el 2013 levemente inferior al $20 \%$ similar durante 18 años. Últimamente, en el 2014 descendió a 14\% y 13.84\% en el 2015, estas menores cifras son coincidentes con la desaceleración de la actividad productiva (PBI) ante la caída de la inversión pública y privada. De otro lado, cabe señalar que si bien es elevado el spread en las entidades del SFP, aún son menores si comparamos con los créditos específicos a pequeños y microempresarios, peor aún si comparamos con los márgenes que generan las entidades no supervisadas por la SBS, como las entidades financieras informales, que ofertan créditos al gran segmento de microempresarios informales.

\section{EL CRÉDITO EN EL PERÚ ENTRE LOS MÁS CAROS DEL MUNDO}

Como se ha afirmado los créditos ofertados por entidades del sistema financiero peruano

\footnotetext{
* Superintendencia de Banca y Seguros del Perú. . (2016). Tasas de Interes. 08 maarzo, 2016, de SBS GOB Sitio web: http://www.sbs.gob.pe/app/pp/seriesHistoricas/paso5_ Descargar.aspx cod $=4 \&$ per $=6 \&$ paso $=3 \&$ secu $=02$
}

se encuentran entre los más caros del mundo. Esto se debe a que registra uno de los más altos márgenes o spread. Por ello es calificado entre los países que registran los peores spread del mundo, característica que se puede apreciar destacando los spread de los años 2010 y 2014, considerando la información del Banco Mundial y de la Superintendencia de Banca y Seguros-SBS. Al destacar los spread como diferencia entre las tasas de los préstamos y depósitos, se observa que en el 2010 nuestro país registró $17.5 \%$ de spread, seguido por otros de Latinoamérica, como Brasil con $31.1 \%$, Paraguay con $24.8 \%$, luego al compararlo con el año 2014 nuestro país registra 14\%, Brasil $21.98 \%$, y Paraguay $16.88 \%$, comportamientos que mantienen spread altos, por los que se les considera como los países con los peores spread del mundo. En cambio, los países que describen bajos spread son considerados como los mejores spread del mundo, como el caso de Estados Unidos que registró $2.77 \%$ en el 2010 y $3.03 \%$ en el 2014, Japón $1.10 \%$ en el 2010 y $0.80 \%$ en el 2014 , Canadá y China menores de 3\% y Chile 3\% en el 2010 y $4.18 \%$ en el 2014. Tales spread del 2010 y $2014^{-\omega}$ se pueden observar en el siguiente cuadro $\mathrm{N}^{\circ} 2$ y gráfico $\mathrm{N}^{\circ} 02$ :

Cuadro $\mathrm{N}^{\circ} 2$. Tasas para préstamos, ahorros y spread en el mundo: 2010 y 2014

\begin{tabular}{l|c|c|c|c}
\hline \multicolumn{1}{c|}{ Paises con mejor spread } & SPRED-2010 & Prestamos-2014 & Ahorros-2014 & SPREAD-2014 \\
\hline Japón & $1.10 \%$ & $1.20 \%$ & $0.40 \%$ & $0.80 \%$ \\
Corea & $1.70 \%$ & $4.30 \%$ & $2.57 \%$ & $1.73 \%$ \\
Canadá & $2.40 \%$ & $3.00 \%$ & $0.55 \%$ & $2.45 \%$ \\
Estados Unidos & $2.77 \%$ & $3.30 \%$ & $0.27 \%$ & $3.03 \%$ \\
Chile & $3.00 \%$ & $8.10 \%$ & $3.92 \%$ & $4.18 \%$ \\
China & $3.10 \%$ & $5.60 \%$ & $2.75 \%$ & $2.85 \%$ \\
México & $4.10 \%$ & $3.60 \%$ & $0.89 \%$ & $2.71 \%$ \\
Singapur & $4.70 \%$ & $5.40 \%$ & $0.19 \%$ & $5.21 \%$ \\
PAISES CON PEOR SPREAD & & & & \\
Uruguay & $6.20 \%$ & $15.50 \%$ & $4.06 \%$ & $10.64 \%$ \\
Perú & $1.40 \%$ & $16.26 \%$ & $2.26 \%$ & $14.00 \%$ \\
Paraguay & $24.80 \%$ & $21.20 \%$ & $4.32 \%$ & $16.88 \%$ \\
Brasil & $31.10 \%$ & $32.00 \%$ & $10.02 \%$ & $24.98 \%$ \\
\hline
\end{tabular}

Gráfico $N^{\circ} 2$. Tasas para préstamos, ahorros y spread en el mundo: 2010 y 2014

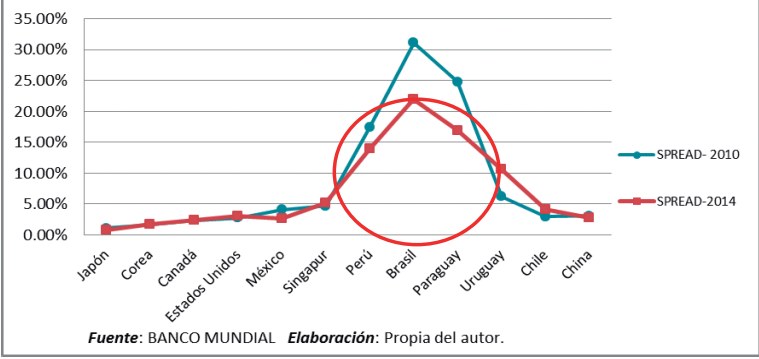

火*** Banco Mundial. (2016). Diferencial de tasas de interés (tasa activa menos tasa pasiva, \%). 04 marzo, 2016, de Datos del Banco Mundial Sitio web: http://datos.bancomundial. org/indicador/FR.INR.LNDP 


\section{PRÉSTAMOS EN MONEDA NACIONAL EXTRANJERA Y EL TIPO DE CAMBIO}

Pese a los spread elevados que describen las entidades del SFP, no significa que los préstamos en moneda nacional y extranjera sean siempre iguales de caros, ya que para el caso de la moneda extranjera varía su costo (tasa de interés) según el tipo de cambio, por lo que resulta necesario conocer los costos de los préstamos y compararlos, considerando las ventajas que presentan cada uno, según el intervalo de tiempo, y de esta manera adoptar la mejor decisión de endeudarse en soles o dólares. En este sentido, el conocimiento del costo efectivo, sea en soles o dólares, elimina la recomendación improvisada y sin sustento, que afirma que el préstamo en soles es más barato, pues el dólar siempre está subiendo y resulta más caro (se refiere a la devaluación). Esto no es cierto, ya que la variación del tipo de cambio puede originar una devaluación o apreciación de la moneda nacional, que conlleve que los préstamos en dólares puedan resultar más baratos. También se comenta que, como la tasa de interés para préstamos en soles es más alta que para dólares, los préstamos en soles son más caros, lo que no es cierto. El costo efectivo del crédito en dólares depende del tipo de cambio (TC) y que ante el libre mercado, varía permanentemente, causando devaluación o apreciación de la moneda nacional.

Para conocer el préstamo más caro o barato entre soles y dólares, se tiene que determinar el costo o tasa efectiva equivalente en moneda nacional, cálculo que comprende el ajuste de la devaluación (+) o apreciación (-) de la tasa efectiva en dólares, resultado que se comparará con la tasa efectiva en moneda nacional. Para ilustrar el cálculo, se aplicará el procedimiento según fórmula:

$$
\text { teq.S } / .=\left[(1+T e \$)^{n}(1+d)^{n}-1\right] \times 100 \%
$$

teq S/: tasa efectiva equivalente anual en soles. Te \$: Tasa efectiva en dólares.

$d$ : Devaluación anual esperada(+) o apreciación (-)

Caso ilustrativo 01: Una entidad bancaria a inicio del 2015 ofrecía préstamo en dólares a una tasa efectiva anual de $7.89 \%$ (TAMEX) y considerando una devaluación esperada de $25.10 \%$ (Var.TC), calcular la tasa efectiva equivalente en soles. Luego comparar con la tasa efectiva para soles de $16.26 \%$ (TAMN) y determinar cuál de los préstamos, en soles o dólares, es más caro.

Aplicando la fórmula: teq. $\$=(1+0.0789)$ * $(1+0.251)-1=0.3065 \ldots . .30 .65 \%$.

Es decir, $30.65 \%>16.26 \%$ en soles, resultando que el préstamo en dólares es más caro que en soles (ver cuadro 03: año 2015).

Caso ilustrativo 02: Una entidad bancaria a inicio del 2004 ofrecía préstamo en dólares a una tasa efectiva anual de $9.66 \%$ (TAMEX) y considerando una apreciación esperada de (-) 5.2\% (Var. $\mathrm{TC})$, calcular la tasa efectiva equivalente anual en soles. Luego comparar con la tasa efectiva para soles de $24.79 \%$ (TAMN) y determinar cuál de los préstamos, en soles o dólares, es más caro.

Aplicando la fórmula: teq. $\$=(1+0.0966)$ * $(1+-0.052)-1=0.0396 \ldots 3.96 \%$.

Es decir, $3.96 \%<24.79 \%$ en soles, resultando que el préstamo en dólares es más barato que en soles (Ver cuadro 3 : año 2004).

Para mayor evidencia, cabe destacar que al caer el tipo de cambio desde 2003 resultaron ventajosos los créditos en dólares debido a la menor tasa de interés que en soles (ver cuadro). Tal evolución de la diferencia de tasas y tipo de cambio se puede observar en el cuadro 3 y gráfico 3 :

Cuadro $\mathrm{N}^{\circ} 3$. Préstamos y tasas de intereses activas (\%): 1992-2015

\begin{tabular}{c|c|c|c|c|c}
\hline AÑO & TAMN & TAMEX & Diferencia & TC & Var. TC \\
\hline 1992 & $135.50 \%$ & $16.90 \%$ & $118.60 \%$ & 1.63 & - \\
1993 & $71.50 \%$ & $15.20 \%$ & $56.30 \%$ & 2.17 & $33.13 \%$ \\
1994 & $39.00 \%$ & $15.20 \%$ & $23.80 \%$ & 2.19 & $0.92 \%$ \\
1995 & $35.10 \%$ & $17.20 \%$ & $17.90 \%$ & 2.32 & $5.94 \%$ \\
1996 & $30.06 \%$ & $16.80 \%$ & $13.26 \%$ & 2.6 & $12.07 \%$ \\
1997 & $30.04 \%$ & $15.60 \%$ & $14.44 \%$ & 2.74 & $5.38 \%$ \\
1998 & $32.06 \%$ & $16.80 \%$ & $13.26 \%$ & 3.16 & $15.33 \%$ \\
1999 & $32.33 \%$ & $14.46 \%$ & $14.44 \%$ & 3.51 & $11.08 \%$ \\
2000 & $32.33 \%$ & $12.46 \%$ & $15.26 \%$ & 3.53 & $0.57 \%$ \\
2001 & $23.84 \%$ & $12.06 \%$ & $17.87 \%$ & 3.44 & $-2.55 \%$ \\
2002 & $20.77 \%$ & $12.16 \%$ & $8.61 \%$ & 3.51 & $2.03 \%$ \\
2003 & $21.02 \%$ & $10.04 \%$ & $10.98 \%$ & 3.46 & $-1.42 \%$ \\
2004 & $24.79 \%$ & $9.66 \%$ & $15.13 \%$ & 3.28 & $-5.20 \%$ \\
2005 & $25.42 \%$ & $9.07 \%$ & $16.35 \%$ & 3.42 & $4.27 \%$ \\
2006 & $23.39 \%$ & $9.86 \%$ & $13.53 \%$ & 3.2 & $-6.43 \%$ \\
2007 & $22.87 \%$ & $10.54 \%$ & $12.33 \%$ & 3 & $-6.25 \%$ \\
2008 & $23.68 \%$ & $10.63 \%$ & $13.05 \%$ & 3.13 & $4.33 \%$ \\
2009 & $22.91 \%$ & $10.30 \%$ & $12.61 \%$ & 2.89 & $-7.67 \%$ \\
2010 & $18.73 \%$ & $8.54 \%$ & $10.19 \%$ & 2.81 & $-2.77 \%$ \\
2011 & $18.69 \%$ & $8.00 \%$ & $10.69 \%$ & 2.7 & $-3.91 \%$ \\
2012 & $19.27 \%$ & $8.05 \%$ & $11.22 \%$ & 2.61 & $-3.33 \%$ \\
2013 & $21.06 \%$ & $8.19 \%$ & $12.87 \%$ & 2.57 & $-1.53 \%$ \\
2014 & $16.26 \%$ & $7.60 \%$ & $8.66 \%$ & 2.55 & $-0.78 \%$ \\
2015 & $16.26 \%$ & $7.89 \%$ & $8.37 \%$ & 3.19 & $25.10 \%$ \\
$2016-$ Feb 23 & $16.04 \%$ & $8.08 \%$ & $7.96 \%$ & 3.47 & $8.78 \%$ \\
\hline
\end{tabular}

Fuente: Banco Mundial.

Elaboración: Propia del autor.

\footnotetext{
Banco Central de Reserva del Perú. (2016). Tipo de cambio promedio del período. 04 marzo, 2016, de BCRP Estadísticas Sitio web: www.bcrp.gob.pe/docs/Estadisticas/Cuadros-Estadisticos/ NC_040.xls
} 
Gráfico $N^{\circ}$ 3. Tipo de cambio en soles por USD: 1992-2016

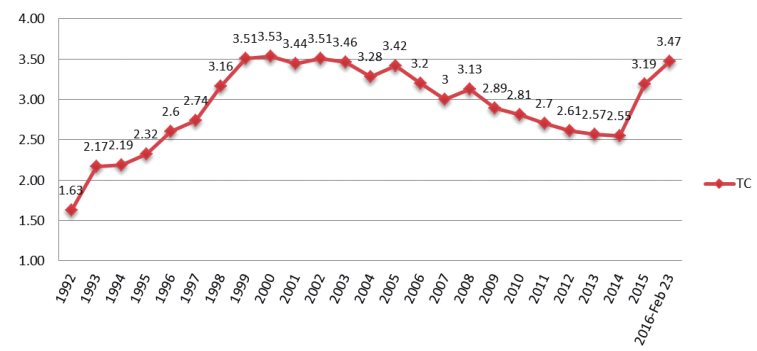

Fuente: Banco Mundial.

Elaboración: Propia del autor.

Gráfico No 3.1. Diferencia de tasas de préstamos en soles y dólares y variación del TC (\%): 1992-2016

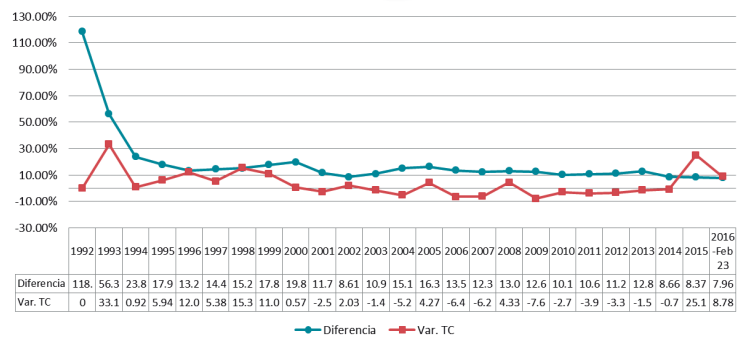

Fuente: Banco Mundial.

Elaboración: Propia del autor.

Del gráfico 3.1, se puede apreciar que cuando la curva de la variación del tipo de cambio está por debajo de la curva de diferencia (tasas de interés para préstamos en soles, TAMN, y las tasas de interés para préstamos en dólares, TAMEX), resultan ventajosos los créditos en dólares, explicado fundamentalmente por la apreciación del sol, cuando se paga menos (-) soles por dólar, variación negativa del tipo de cambio (2003-2014); diferente a la significativa devaluación del $25.1 \%$ en el 2015 , cuando la curva de la variación de TC está por encima de la curva relacionada a la diferencia.

De otro lado, el spread en dólares como en soles ha bajado levemente, pero se mantiene elevado. En cuanto al spread en dólares elevado, es explicado por la baja tasa de interés por los ahorros, TIPMEX, ya que la tasa de interés para créditos en dólares en el mundo ha bajado drásticamente debido a la crisis internacional agravada por la recesión mundial, provocando que el costo del fondeo sea muy bajo en el mercado internacional. Asimismo, el riesgo de los usuarios en el mercado doméstico es elevado, lo que conlleva que la tasa para los créditos en dólares sea alta. Tal evolución del spread se observa en el siguiente cuadro 4 :
Cuadro No 4. Préstamos y ahorros en moneda extranjera

\begin{tabular}{c|c|c|c}
\hline AÑO & TAMEX & TIPMEX & MARGEN O SPREAD \\
\hline 1992 & $16.90 \%$ & $5.78 \%$ & $11.12 \%$ \\
1993 & $15.20 \%$ & $5.00 \%$ & $10.20 \%$ \\
1994 & $15.20 \%$ & $4.90 \%$ & $10.30 \%$ \\
1995 & $17.20 \%$ & $6.20 \%$ & $11.00 \%$ \\
1996 & $16.80 \%$ & $5.70 \%$ & $11.10 \%$ \\
1997 & $15.60 \%$ & $5.20 \%$ & $10.40 \%$ \\
1998 & $16.80 \%$ & $5.40 \%$ & $11.40 \%$ \\
1999 & $14.46 \%$ & $4.84 \%$ & $9.62 \%$ \\
2000 & $12.46 \%$ & $4.60 \%$ & $7.86 \%$ \\
2001 & $12.46 \%$ & $3.48 \%$ & $8.58 \%$ \\
2002 & $12.06 \%$ & $1.58 \%$ & $10.58 \%$ \\
2003 & $12.16 \%$ & $1.13 \%$ & $8.91 \%$ \\
2004 & $10.04 \%$ & $1.06 \%$ & $8.60 \%$ \\
2005 & $9.66 \%$ & $1.52 \%$ & $7.55 \%$ \\
2006 & $9.07 \%$ & $2.04 \%$ & $7.82 \%$ \\
2007 & $9.86 \%$ & $2.28 \%$ & $8.26 \%$ \\
2008 & $10.54 \%$ & $2.42 \%$ & $8.21 \%$ \\
2009 & $10.63 \%$ & $1.35 \%$ & $8.19 \%$ \\
2010 & $9.54 \%$ & $0.81 \%$ & $7.54 \%$ \\
2011 & $8.35 \%$ & $0.69 \%$ & $7.33 \%$ \\
2012 & $8.00 \%$ & $0.80 \%$ & $7.25 \%$ \\
2013 & $8.05 \%$ & $0.45 \%$ & $7.74 \%$ \\
2014 & $8.19 \%$ & $0.37 \%$ & $7.23 \%$ \\
2015 & $7.60 \%$ & $0.33 \%$ & $7.56 \%$ \\
\hline
\end{tabular}

Fuente: Banco Mundial.

Elaboración: Propia del autor.

\section{TASAS DE INTERÉS INTERNACIONALES PARA PRÉSTAMOS AÚN BAJA}

El costo de dinero en el mercado internacional ha bajado drásticamente debido a la crisis internacional del 2008, y ante la recesión y el elevado endeudamiento en países europeos, se adoptó la política de estímulo monetario, abaratando el costo de la deuda. Para observar este comportamiento de las bajas tasas de interés, destacaremos, en primer término, la tasa interbancaria del mercado de Londres, LIBOR, considerada como el tipo de interés interbancario, medio al que importantes bancos otorga préstamos a corto plazo en el mercado de Londres. Estos tipos de interés del LIBOR se publican diariamente, debido a que bancos y muchas instituciones financieras lo utilizan como interés básico o referente, y las disminuciones o aumentos del LIBOR pueden afectar las tasas de interés de los créditos y otros productos bancarios, como hipotecas y depósitos de ahorros.

Así, en la baja tasa de interés en el mercado internacional, expresada en la tasa Libor, se observa la disminución drástica desde el 2007, en que registró $5.34 \%$ para caer a $1.16 \%$ en el 2015 , considerando la tasa de interés Libor y cargos fi- 
nancieros. Tal evolución de la tasa Libor se observa en los siguientes cuadros $\mathrm{N}^{\circ} 5$ y 5.1 :

\begin{tabular}{|c|c|c|c|c|c|}
\hline \multirow[b]{2}{*}{ Período } & & \multicolumn{2}{|c|}{ Tasa basada en LIBOR ${ }^{1}$} & \multirow{2}{*}{$\begin{array}{c}\text { Margen de } \\
\text { préstamos del } \\
\text { BID }^{3}\end{array}$} & \multirow{2}{*}{$\begin{array}{l}\text { Tasa de } \\
\text { Interés }\end{array}$} \\
\hline & & $\begin{array}{c}\text { LIBOR } \\
\text { 6-meses }\end{array}$ & $\begin{array}{l}\text { Margen de } \\
\text { Fondeo }{ }^{2}\end{array}$ & & \\
\hline 2015 & 2do. Semestre & $0.53 \%$ & $-0.22 \%$ & $0.85 \%$ & $1,10 \%$ \\
\hline 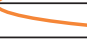 & 1er. Semestre & $0.38 \%$ & $-0.22 \%$ & $0.85 \%$ & $1,01 \%$ \\
\hline \multirow[t]{2}{*}{2014} & 2do. Semestre & $0.33 \%$ & $-0.21 \%$ & $0.85 \%$ & $0,97 \%$ \\
\hline & 1er. Semestre & $0.33 \%$ & $-0.21 \%$ & $0.85 \%$ & $0,97 \%$ \\
\hline \multirow[t]{2}{*}{2013} & 2do. Semestre & $0.40 \%$ & $-0.21 \%$ & $0.84 \%$ & $1,03 \%$ \\
\hline & 1er. Semestre & $0.46 \%$ & $-0.23 \%$ & $0.84 \%$ & $1,07 \%$ \\
\hline \multirow[t]{2}{*}{2012} & 2do. Semestre & $0.72 \%$ & $-0.23 \%$ & $0.62 \%$ & $1,11 \%$ \\
\hline & 1er. Semestre & $0.76 \%$ & $-0.23 \%$ & $0.62 \%$ & $1,15 \%$ \\
\hline \multirow[t]{2}{*}{2011} & 2do. Semestre & $0.45 \%$ & $-0.22 \%$ & $0.80 \%$ & $1,03 \%$ \\
\hline & 1er. Semestre & $0.47 \%$ & $-0.21 \%$ & $0.80 \%$ & $1,05 \%$ \\
\hline \multirow[t]{2}{*}{2010} & 2do. Semestre & $0.59 \%$ & $-0.21 \%$ & $0.95 \%$ & $1,13 \%$ \\
\hline & 1er. Semestre & $0.39 \%$ & $-0.21 \%$ & $0.95 \%$ & $1,13 \%$ \\
\hline \multirow[t]{2}{*}{2009} & 2do. Semestre & $0.85 \%$ & $-0.20 \%$ & $0.95 \%$ & $1,60 \%$ \\
\hline & 1er. Semestre & $1.74 \%$ & $-0.21 \%$ & $0.30 \%$ & $1,83 \%$ \\
\hline \multirow[t]{2}{*}{2008} & 2do. Semestre & $3.10 \%$ & $-0.21 \%$ & $0.30 \%$ & $3,19 \%$ \\
\hline & 1er. Semestre & $2.95 \%$ & $-0.20 \%$ & $0.15 \%$ & $2,90 \%$ \\
\hline \multirow[t]{2}{*}{2007} & 2do. Semestre & $5.40 \%$ & $-0.21 \%$ & $0.15 \%$ & $5,34 \%$ \\
\hline & 1er. Semestre & $5.40 \%$ & $-0.21 \%$ & $0.15 \%$ & $5,34 \%$ \\
\hline
\end{tabular}

1. Tasa de interés basada en la tasa LIBOR a 6 meses, la cual es determinada dos veces al año, en febrero y agosto.

- Tasa de interés basada en la tasa LIBOR a 6 meses, la cual es determinada dos veces al año, en febrero y agosto.

- Corresponde al margen de fondeo del BID sobre/debajo de la tasa LIBOR a 6 meses.

- Corresponde al margen para préstamos del BID 4.Tasa base (LIBOR) más los cargos financieros.

Como referencia, la tasa Libor a 12 meses es de $\mathbf{0 . 8 3 4 1 5}$ \% dólares (22 Oct. 2015)

\begin{tabular}{c|c|c|ccc}
\hline Fecha & $\begin{array}{c}\text { Libor a 1 } \\
\text { mes }\end{array}$ & $\begin{array}{c}\text { Libor a 2 } \\
\text { meses }\end{array}$ & $\begin{array}{c}\text { Libor a 3 } \\
\text { meses }\end{array}$ & $\begin{array}{c}\text { Libor a 6 } \\
\text { meses }\end{array}$ & $\begin{array}{c}\text { Libor a 12 } \\
\text { meses }\end{array}$ \\
\hline $22 / 10 / 2015$ & $0,19695 \%$ & $0,25300 \%$ & $0,31990 \%$ & $0,52840 \%$ & $0,83415 \%$ \\
$21 / 10 / 2015$ & $0,19480 \%$ & $0,25100 \%$ & $0,31640 \%$ & $0,52690 \%$ & $0,83140 \%$ \\
$20 / 10 / 2015$ & $0,19650 \%$ & $0,25100 \%$ & $0,32040 \%$ & $0,52440 \%$ & $0,82815 \%$ \\
$19 / 10 / 2015$ & $0,19600 \%$ & $0,24950 \%$ & $0,31665 \%$ & $0,51790 \%$ & $0,82615 \%$ \\
$16 / 10 / 2015$ & $0,19425 \%$ & $0,24950 \%$ & $0,31715 \%$ & $0,51840 \%$ & $0,82565 \%$ \\
$15 / 10 / 2015$ & $0,19675 \%$ & $0,24975 \%$ & $0,31515 \%$ & $0,51590 \%$ & $0,81640 \%$ \\
$14 / 10 / 2015$ & $0,19900 \%$ & $0,25160 \%$ & $0,31705 \%$ & $0,52015 \%$ & $0,82890 \%$ \\
\hline
\end{tabular}

Como referencia la tasa Libor a 12 meses, al 22 de octubre del 2015 fue de $0.83415 \%$ :

Con respecto a la TASA PRIME RATE, considerada como tasa preferencial creada en 1993 en los EE.UU., en que los bancos de esta plaza aplican a los importantes créditos y a empresas de primer nivel. La tasa PRIME RATE más baja fue entre 1934 y 1947 , cuando se registró $1.90 \%$, luego la tasa más alta fue de $20 \%$ en 1981 .

La baja tasa de interés en el mercado internacional, expresada en la tasa PRIME RATE, también se observa que ha disminuido drásticamente desde el 2007 cuando se registró $8.0 \%$, para caer a $3.25 \%$ en octubre del 2015. Tal evolución de la tasa PRIME RATE se observa en los siguientes cuadros $\mathrm{N}^{\circ}$ 6: Prime Rate History y 6.1:

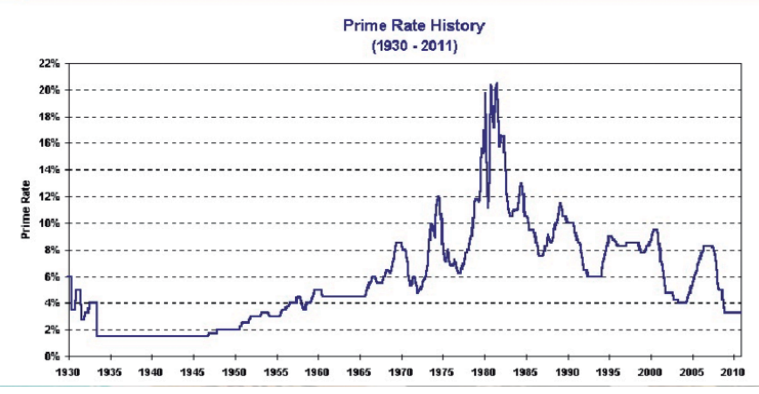

Como referencia la tasa PRIME RATE, al 28 de octubre del 2015 registra 3.25\%:

\begin{tabular}{c|c}
\hline \multicolumn{2}{c}{$\mathbf{2 0 1 5}$} \\
\hline Fecha & Prime rate \\
\hline $28 / 10 / 2015$ & $3,25 \%$ \\
$27 / 10 / 2015$ & $3,25 \%$ \\
$26 / 10 / 2015$ & $3,25 \%$ \\
$23 / 10 / 2015$ & $3,25 \%$ \\
$22 / 10 / 2015$ & $3,25 \%$ \\
$21 / 10 / 2015$ & $3,25 \%$ \\
$20 / 10 / 2015$ & $3,25 \%$ \\
$19 / 10 / 2015$ & $3,25 \%$ \\
$16 / 10 / 2015$ & $3,25 \%$ \\
\hline
\end{tabular}

De otro lado, la TASA DE REFERENCIA de los EE. UU, FED, conocida por el acrónimo FED, Federal Reserve System, llamada también Reserva Federal, institución independiente, como banco central de los EE.UU., propiedad de grandes bancos privados, que tiene como función principal la estabilidad del sistema financiero de los Estados Unidos. Uno de los principales referentes del mundo, dado que las reuniones de las autoridades de la FED, para decidir si sube o baja la tasa, causa preocupación mundial, ya que el alza o la baja de la tasa de referencia impacta directamente en los mercados financieros internacionales.

La baja tasa de interés en los mercados internacionales también se puede apreciar en la tasa de referencia de los EE. UU. FED, ya que de 5.25\% aprobado en junio del 2006 por Bernanke, bajó en diciembre del 2008 al nivel cercano a cero para afrontar la recesión y el elevado endeudamiento mundial, manteniéndose por siete años, hasta que recientemente el 16 de diciembre 2015, se dispuso elevarlo levemente en 25 puntos básicos, para ubicarse entre el $0.25 \%$ y el $0.5 \%$. Tal evolución de los tipos de interés en EE.UU.-FED, se observa en los siguientes gráficos: 


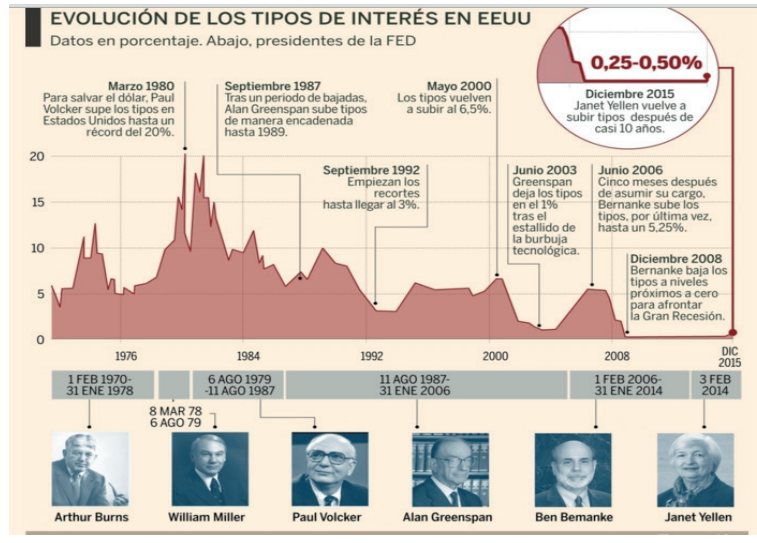

El panorama en el mercado peruano cuando la tasa FED estuvo en el nivel cercano a cero fue atractivo para la inversión extranjera, pero dada la desconfianza e incertidumbre en nuestro país, no se pudo aprovechar esta oportunidad. A nivel del mercado financiero, la moneda nacional adquiere fortaleza, pudiendo surgir alguna volatilidad del tipo de cambio por corto período.

Cuadro No6. Pérdida nominal de Ahorro en soles: 1992-2015

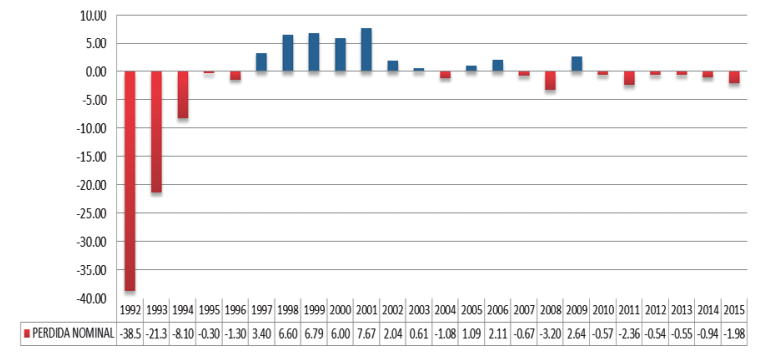

Fuente: Banco Mundial.

Elaboración: Propia del autor.

\section{ENCARECIMIENTO DEL COSTO DEL DINERO Y LA INFORMALIDAD}

Alrededor del $70 \%$ de nuestra economía es informal, entendiéndose que los últimos gobiernos desde hace 60 años han desatendido este segmento mayoritario de la sociedad peruana, ocupándose solo del 30\% de la organización empresarial del país que es formal, explicándose así el estado actual de desorden, desigualdad, pobreza y precariedad en que vive nuestra sociedad. Si calificamos a la gestión de los Gobiernos antes referidos, estos estarían desaprobados y de acuerdo a la escala vigesimal (base de 20), tendrían la nota de $06(.03 * 20)$. Estableciéndose como característica de ineficiente e incapaz a la gestión gubernamental al no haber tenido la capacidad de ampliar la formalización en nuestro país, siquiera elevarlo al $50 \%$.

Respecto a la informalidad en nuestro país, también se da en el mercado financiero a través de entidades no supervisadas ni reguladas por la SBS, quienes ofertan el crédito más caro en el país. Estas entidades, difundidas como de inversión, prestamistas, prendarias y ONG, ofertan diferentes modalidades de préstamo de manera informal. Algunas la hacen mediante sistemas de juntas, grupos solidarios, quienes mutuamente se garantizan; otras en pequeños mercados o comercios, sin necesidad de garantía, prestan dinero con el compromiso de que paguen altas tasas de interés ("usura"). Las tasas a pagar pueden ser interés mensual del $10 \%, 20 \%, 25 \%$ o más, con capitalización diaria y pagos diarios, semanal o mensual, por lo que resulta frecuente que se asuma una tasa efectiva anual (TEA) del $231.35 \%$, 993.57\%, o $1883.74 \%$, respectivamente. Tal impacto del crédito informal conlleva una mayor precariedad de los usuarios y, a los microempresarios, un mayor deterioro de sus escasos patrimonios y condiciones socioeconómicas. Si bien en la última década más de 4 millones de personas han accedido al crédito formal, aún hay muchos peruanos en la informalidad, sin historia y sin cultura financiera.

Según el Instituto Peruano de Economía (IPE), el $82 \%$ de las personas que obtienen préstamos informales pagan por lo menos un interés mensual del $10 \%$ o una tasa efectiva anual (TEA) mayor del $200 \%$, y el $18 \%$ paga un interés mensual del $20 \%$ o una TEA mayor del $700 \%$. También destaca que $68.5 \%$ conoce la tasa de interés de su préstamo y el 31.5\% no conoce.

El costo del crédito informal es más caro que el crédito en el sistema financiero formal, ya que por un préstamo de consumo se paga una TCEA que va de $32 \%$ hasta $197 \%$, menor que la tasa del $231.35 \%$ o $1,873.74 \%$, y más, que se paga por préstamo informal.

La situación del encarecimiento crediticio se puede mejorar con mayor competencia de nuevas entidades financieras, y dando prioridad a los microempresarios con crédito de bajo costo, más aún en una economía de libre mercado, que permite cualquier mecanismo de competencia, sin fijar o controlar las tasas de interés. En este sentido, reiteraremos una propuesta, dada a conocer en nuestro artículo del año 2003.

\section{DISCUSIÓN}

De acuerdo a la evolución de las entidades del sistema financiero vigente, se establece que la tendencia es profundizar su atención en las grandes, medianas y pequeñas empresas y en menor atención a las microempresas. 
De modo que ya es momento de reaccionar y repensar en una nueva alternativa para préstamos a microempresas y viable, considerando mínimos costos aprovechando infraestructura, espacios de mercado y capacidad subutilizada del Estado como la institución COFIDE, creada para canalizar principalmente financiamiento a empresas públicas, cuando imperaba el Estado-empresario, actualmente sin vigencia al imperar la economía de libre mercado.

La propuesta-alternativa es convertir a COFIDE en "Banco de las microempresas" (BANPE), una entidad financiera de libre competencia como vehículo de financiamiento directo a mercados organizados, como clúster, etc., ofertando créditos a bajo costo.

Para organización y funcionamiento del Banco, se contará con el apoyo y promoción del Gobierno, sin que signifique desembolsos de recursos financieros presupuestales, sino poniendo a disposición la capacidad e infraestructura de COFIDE, y contará con un sistema de información estructurado a través de centro de riesgos y seguros, centro de oferta y demanda, centro de formalización y desarrollo de hipotecas, fondo de garantía para préstamos a la pequeña y microempresa, enmarcada en una nueva cultura crediticia que articule la inversión productiva y el ahorro interno voluntario.

EI gobierno estaría en el mejor momento para poner en funcionamiento un Banco para el desarrollo de jóvenes emprendedores y microempresarios, dada la oportunidad actual en que el financiamiento del exterior está con bajas tasas de interés internacionales, como la tasa Libor en dólares a 12 meses, que está en $1.16 \%$ anual. Este BANPE fortalecerá su estructura financiera con financiación de las propias microempresas, y fondeo mediante líneas de crédito del exterior baratas, lo que le permitirá viabilizar préstamos para microempresas a tasas competitivas.

iA mayor competencia, mejor oferta; a mayor oferta financiera, menor tasa de interés!

\section{CONCLUSIONES}

1. Los créditos ofertados por entidades del sistema financiero peruano se encuentran entre los más caros del mundo, al registrar uno de los más altos spread, como el del
2010, con 17.5\%, seguido por Paraguay con $24.8 \%$, Brasil con $31.1 \%$, que se mantienen altos en el 2014 en que nuestro país registra 14\%, Paraguay $16.88 \%$ y Brasil $21.98 \%$, países con los peores spread del mundo.

2. Los préstamos en moneda nacional y extranjera no siempre son iguales de caros, ya que para el caso de la moneda extranjera varía su costo según el tipo de cambio, evidenciándose que al caer el tipo de cambio desde 2003, resultaron más baratos los créditos en dólares en comparación con los préstamos en soles.

3. El costo de los préstamos en el mercado internacional ha bajado drásticamente como se puede apreciar en la tasa Libor, que se encuentra en $1.16 \%$ actualmente (2015), muy por debajo del 5.34\% que registró en el 2007.

4. Los ahorros en el sistema financiero peruano han generado pérdida o tasa real negativa, como se puede observar desde el año 2007 a la fecha, en que la inflación supera a la tasa de interés que han pagado por ahorros.

5. El deterioro patrimonial de las microempresas se ven agravadas porque el $50 \%$ de estas empresas financian sus operaciones a través de los prestamistas informales y lo hacen a tasas muy elevadas. Debe encararse la problemática de las microempresas, con una estrategia de apoyo y promoción efectiva, considerando la propuesta alternativa de convertir COFIDE en Banco de las microempresas (BANPE), no de Fomento, sino de acuerdo a las reglas de mercado, orientado a impulsar la actividad productiva y a revertir el grave nivel de informalidad.

\section{REFERENCIAS BIBLIOGRÁFICAS}

ASBANC (2015). Contexto Internacional, Economía y Banca Peruana.

BCRP (2016). Tipo de cambio promedio del período. Estadísticas y publicaciones.

SBS (2016). Diferencial de tasas de interés tasa activa menos tasa pasiva. Datos del Banco Mundial. 